\title{
Multilingualism as a Chance - A Set of Conferences About the Promotion of Multilingualism
}

The long standard practice of research on language teaching and learning has always assumed that monolingualism was the norm. Nowadays more and more people of the world population are able to communicate in several languages; some of them are even growing up in environments where they know and/or speak two or more languages. Even in the context of this group, multilingualism does not necessarily represent a constant feature, but remains a variable competence that is permanently influenced. Keeping that in mind, the targeted promotion of multilingualism is a very important task and goal because multilingualism is seen as a personal and professional necessity that can help us to be mobile and successful as language and intercultural communication skills are a distinct plus for everybody.

Multilingualism is also a term with open semantics. The term "multilingualism" (sometimes used as a synonym for "bilingualism") can also mean very "different realities". Linguistics describes the different understandings and usages of the term systematically in literature usually by differentiating the term for various contexts/ groups: individual, social, and (occasionally also) institutional multilingualism (cf. Council of Europe, 2001, p. 4). The conferences about the promotion of multilingualism are attempts to use the positive potential of experiences with the supporting concepts and didactics being used to develop a greater competence in all three forms/uses of the word "multilingualism". The conferences under the title of "Multilingualism as a Chance" aim to promote language and cultural diversity of people and also foreign language learning in Europe. The sequence of six conferences, which were staged between 2009 and 2015, tried to identify regions in Europe in which people live in environments where more than one language is used in everyday life and learn even more languages in school.

The Department of German as a Foreign and Second Language of the University of Kassel and the Language Institute of the Volkshochschule (VHS) Region Kassel organized the most recent conference of "Multilingualism as a Chance". This conference took place from the $3^{\text {rd }}$ to the $5^{\text {th }}$ of July 2017 in Kassel (Germany). The priority of 
124 this conference was to try to gather contributions for an "atlas of multilingualism" in Europe.

The international consortium that consists of representatives from different universities in Belgium, Finland, Poland, Austria, Switzerland, Germany, and the VHS Region Kassel organized a congress for about 170 participants. After two years of preparation, more than 60 speakers were able to share their expertise.

There were seven sections of the conference divided according to their focus on answering one of the following questions:

1. What are the consequences of the concurrent trends of globalisation and regionalisation for concepts in education?

2. How can we make use of the potential of multilingualism in the different educational systems in Europe?

3. What is the role and how are the dynamics of multilingualism in the multilingual regions of Europe?

4. How do multilingual regions in Europe organize the teaching of the Cognitive Academic Language Proficiency for cultural or lingual minorities?

5. What is the role of the mother tongues of migrants when learning the second languages of their destination countries?

6. What is the role of multilingualism in striving for personal, cultural and social identity?

Three experts held the plenary speeches. The first was Katharina Brizić from the University in Freiburg. She presented data that had been collected together from children, parents and teachers in various primary schools in Vienna and Istanbul. The data showed the memories of the research participants and how they formulate these syntactically and how they perceive the problems they have to solve in the integration on the basis of their culture. Jürgen Trabant, from the Humboldt-University Berlin, held the second plenary talk. The message of his speech was the support of the idea of protecting and promoting many languages in Europe, rather than only promoting and accepting English as the sole common language of Europe. One of the arguments was the idea that through learning languages we learn also about culture and tolerance for others. The Polish speaker Monika Witt from the University in Nysa argued for more international co-operation in the tertiary education of the future language teachers.

I also took part in this conference by presenting a paper about a project based on educational cooperation in the border region of AT-CZ (BIG) in which I am involved. The most important focal points of the project are: the development of guidelines and teaching materials on the topic of "multilingual acquisition" and its evaluation, training of teachers, and cross-border networking of kindergartens, schools, training institutions, and (school) authorities. The main role in the project play kindergartens as institutions where foreign language learning starts for many children (97 kindergartens in Lower Austria and 10 kindergartens in the Czech Republic require the children to learn the language of their neighbouring country). Similarly to other 
reports and contributions on this topic (Regional Multilingualism), the main message

of the paper was to encourage the efforts being made to support multilingualism for effective communication in border regions (similarly to e.g. German-Polish, Italian-Austrian regions etc.). The participants discussed teaching methods that had been proven to be successful and suggested further ways of instructional support.

Other various research projects were also presented in the Poster Section which enabled discussion on current and frequent topics such as: comparison how learning of bilingual children is supported in schools in different countries (California, Germany, and Poland), what influence of teenager/youth language can be found in the language of bilingual pupils, or how to support the literacy of migrants.

The conference allowed teachers, PhD. students and experts in the area of didactics, research and practice of the development of multilingualism to share their views. The topic of multilingualism was also reflected in new teaching and learning materials (handbooks, textbooks) presented by various publishing houses. The support of multilingualism was articulated as a fundamental general educational strategy in respect to new challenges connected to a growing number of children with other mother tongues and the need of mutual communication across borders. The consortium decided that the next conference with the title "Multilingualism as a Chance" would take place in Klagenfurt in Austria.

\section{References}

Council of Europe (2001). Common European Framework of Reference for Languages: Learning, Teaching, Assessment. Cambridge: Cambridge University Press. 